ISSUES AND INNOVATIONS IN NURSING PRACTICE

\title{
Parent or nurse? The experience of being the parent of a technology-dependent child
}

\author{
Susan Kirk BNurs MSc PhD RGN RHV RM DN \\ Research Fellow, School of Nursing, Midwifery and Social Work, University of Manchester, Manchester, UK \\ Caroline Glendinning BA MPhil \\ Professor of Social Policy, Social Policy Research Unit, University of York, York, UK \\ Peter Callery BA MSc PhD RN RSCN \\ Professor of Children's Nursing, School of Nursing, Midwifery and Social Work, University of Manchester, Manchester, UK
}

Accepted for publication 6 July 2004

\author{
Correspondence: \\ Susan Kirk, \\ School of Nursing, \\ Midwifery and Social Work, \\ Coupland 3, \\ Oxford Road, \\ Manchester M13 9PL, \\ UK. \\ E-mail:sue.kirk@manchester.ac.uk
}

KIRK S., GLENDINNING C. \& CALLERY P. (2005) Journal of Advanced Nursing 51(5), 456-464

Parent or nurse? The experience of being the parent of a technology-dependent child Aims. This paper reports a study exploring parents' experiences of caring for a child who is dependent on medical technology, and in particular of performing clinical procedures on their own children.

Background. A group of children with a continuing need for the support of medical technology have emerged in community settings as a result of medical advances and government policies. Caring for these children has a significant social and emotional impact on parents, because of their specialized and intensive care needs. Obtaining appropriate and coordinated home support services is problematic.

Methods. Grounded theory techniques were used, and in-depth interviews were conducted with the parents of 24 children.

Findings. Parents' accounts revealed that their constructions of parenting were shaped by the nature of their role in caring for their child and by the transformation of their homes by medical equipment and personnel. They described themselves as having a role that had both parenting and nursing dimensions. Parents managed this tension and defined their role and relationship to their child to be primarily one of parenting by differentiating parental care-giving and its underpinning knowledge from that of professionals, particularly nurses.

Conclusions. Parenting a technology-dependent child alters the meaning of parenting. Professionals need to recognize that providing care has a substantial emotional dimension for parents, and that they need opportunities to discuss their feelings about caregiving and what it means for their parenting identity and their relationship with their child. A key professional nursing role will be giving emotional support and supporting parents' coping strategies. Parents' perceptions of nurses raise questions about whether nurses' caregiving is individualized to the needs of the child and family, and whether parental expertise is recognized.

Keywords: children, complex healthcare needs, home care, nursing, parenting 


\section{Background}

Medical advances in the care of pre-term infants, infants with congenital impairments and children with chronic illnesses and cancer have led to the emergence of a group of children who need the support of medical technologies such as mechanical ventilation and parenteral nutrition. Accompanying these medical advances has been a move to care for such children at home rather than in hospital. This has led to complex nursing care, involving sometimes highly technical procedures, being carried out in the home, by parents. However, little is known about how parents experience providing this complex nursing care for their children or how this role might influence their identity as parents.

\section{Parents' experiences of caring for a technology-dependent child}

Research has suggested that caring for a technology-dependent child can be socially isolating for parents (Diehl et al. 1991, McKeever 1991, Teague et al. 1993, Patterson et al. 1994, Cohen 1999, Townsley \& Robinson 2000). They can experience sleep deprivation, stress, anger and depression (McKeever 1991, Leonard et al. 1993, Teague et al. 1993, Patterson et al. 1994, Townsley \& Robinson 2000). One source of such anxiety is the nature of the care, which may not only be potentially dangerous but may also involve parents in inflicting pain on their own children (Jennings 1990, McKeever 1991, Wilson et al. 1998, Atkin \& Ahmad 2000). Parents can feel overburdened by the continuing care demands, and increased rates of family stress and relationship problems have been identified (Diehl et al. 1991, Leonard et al. 1993, Teague et al. 1993, Patterson et al. 1994, Petr et al. 1995).

Obtaining appropriate home support services has been reported to be difficult and problems relating to fragmentation and poor co-ordination are repeatedly cited (Young et al. 1988, Diehl et al. 1991, McKeever 1991, Youngblut et al. 1994, Petr et al. 1995, Kirk 1999). Studies have highlighted parental concerns over the competency of nursing staff supporting them at home and identified the presence of problematic parent-professional relationships because of these concerns and conflicts over care-giving (Jennings 1990, Diehl et al. 1991, McKeever 1991, Townsley \& Robinson 2000).

Qualitative studies have revealed that parents actively attempt to manage the impact of caring on themselves and their families by drawing on internal coping resources and by using a range of skills and strategies (McKeever 1991, Wilson et al. 1998). However, previous research, while describing the problems experienced by families, has not examined how parents experience and make sense of parenting when a child is dependent on technology. Indeed, few studies have explored the meaning of child disablement for parents (Voysey 1975, Gregory 1994).

\section{The social construction of parenting}

Parenting is an umbrella term encompassing the activities and skills performed by adults who provide child rearing and child care-giving (Arendell 1997). It has been defined as

a process of tasks, roles, rules, communication, resources and relationships...parenting involves the skilful and creative use of knowledge, experience and technique. (Horowitz 1993, p. 45)

Parents' actions are directed at meeting the wide range of needs that children have, for example, physical care, love, security, material provision, protection, and encouragement in their development (Rapoport et al. 1978, Arendell 1997). Parenting is defined by the presence of a social relationship between parent and child - a relationship that is being continuously negotiated and which changes over time. It is also viewed as a process of decreasing responsibility, with children assuming responsibility for meeting their own needs over time (Quah 1990). However, parenting a technologydependent child extends these usual ideas of parenting and parenting roles.

Parenting is a dynamic social process as the meaning of parenthood is continuously being reshaped and redefined (Bjornberg 1992, Arendell 1997). Although the broad objectives of parenting are relatively stable (for example, meeting children's physical care needs), how these objectives are defined and understood are reinterpreted and reconstructed (Arendell 1997). Parenting is not solely a personal activity shaped by individual characteristics, experiences and values. Its meaning is fundamentally influenced by social factors such as demographic changes, historical events; cultural norms, values and traditions; societal organization and systems of stratification; and dominant ideologies of parenting (Glenn 1994, Harkness et al. 1996, Arendell 1997). Although parenting is now subject to monitoring by professionals, with the state having a right and duty to intervene when and where it deems necessary, day-to-day parenting remains largely a private activity (Bjornberg 1992).

Images of parenting in the media not only foster stereotypes but present often unattainable visions (Arendell 1997). These images are based on healthy, able-bodied children, excluding parents with disabled children from the category of parenthood as constructed in Western society (Gregory 1994). Parents of disabled children do not have a model on 
which to base their actions and reactions, as they cannot relate their experiences of parenthood to their own experience of being parented or to social constructions of parenting (Rapoport et al. 1978). Consequently, they have to come to terms not only with the loss of a 'normal' child and family life, but also with loss of their expectations of 'normal' parenthood. Thus, for the parents of a technology-dependent child, the nature of their parenting role is very different from everyday ideas of parenting as it is extended to incorporate nursing activities. It addition it has been transformed into a public activity, conducted under the gaze of healthcare professionals and other workers.

\section{The study}

\section{Aim}

The aim of the study was to discover how parents experience caring for a technology-dependent child.

\section{Design}

Qualitative research methods using grounded theory techniques (Glaser 1992, Strauss \& Corbin 1998) were used to obtain in-depth understanding of parents' experiences.

\section{Participants}

Families were recruited via three specialist children's hospitals in England with the assistance of nurse specialists and hospital consultants. Families were initially purposively sampled to ensure that the sample incorporated diversity in terms of a range of technologies, length of time that the children had been at home. and nursing support services in the home. Subsequent sampling was driven by the emerging conceptual framework, and sample size was determined by theoretical saturation.

The research participants were 23 mothers and 10 fathers of 24 children who were dependent on technology. Nine interviews were conducted with both parents present. Four of the families were headed by lone mothers and one family in the sample was from a minority ethnic group. The characteristics of the children are presented in Table 1.

\section{Data collection}

In-depth interviews lasting between 1 and 3 hours were conducted with 24 parents in their own homes. Parents were informed that the aim of the study was to discover what it was like to be the parent of a technology-dependent child.
Table 1 Characteristics of the children in the study $(n=24)$

\begin{tabular}{|c|c|}
\hline Characteristic & Number \\
\hline \multicolumn{2}{|l|}{ Technological dependence } \\
\hline Tracheostomy & 10 \\
\hline Oxygen therapy & 8 \\
\hline Mechanical ventilation & 6 \\
\hline Intravenous drugs & 4 \\
\hline Parenteral nutrition & 2 \\
\hline Peritoneal dialysis & 2 \\
\hline Others (e.g. gastrostomy) & 13 \\
\hline \multicolumn{2}{|c|}{$\begin{array}{l}\text { Number of technologies on which the children } \\
\text { were dependent }\end{array}$} \\
\hline 1 & 6 \\
\hline 2 & 15 \\
\hline 3 & 3 \\
\hline \multicolumn{2}{|l|}{ Gender } \\
\hline Male & 13 \\
\hline Female & 11 \\
\hline \multicolumn{2}{|l|}{ Age (years) } \\
\hline Under 5 & 13 \\
\hline $5-11$ & 6 \\
\hline $12-18$ & 5 \\
\hline \multicolumn{2}{|c|}{ Duration of technology-dependence } \\
\hline Since birth & 13 \\
\hline Following birth & 11 \\
\hline \multicolumn{2}{|c|}{ Length of time since hospital discharge (years) } \\
\hline Less than 1 & 8 \\
\hline $1-3$ & 11 \\
\hline $4-6$ & 1 \\
\hline $7-9$ & 1 \\
\hline 10 or more & 2 \\
\hline
\end{tabular}

Most enquired at the beginning or early on in the interview whether or not the researcher (SK) was a parent herself. Discovering that she was appeared to give them a sense that there was or could be a shared sense of understanding. Shared status as parents may have reduced inequality in the relationship between interviewer and interviewee and enhanced rapport. However, analysis was also informed by the potential for parents to seek to present themselves as morally competent to another parent.

A topic guide provided general direction for the interview. Broad, open-ended questions were used to elicit information, with probing for further detail. Interviews began with asking parents about how their child came to be technologydependent and then moved on to explore their experiences of caring for the child. Questions became more focused and specific as analysis progressed and the categories emerged. Parents were encouraged to direct the conversation into areas of importance for them. All interviews were tape recorded and transcribed verbatim, apart from one in which detailed notes were recorded. 


\section{Ethical considerations}

Approval to conduct the study was obtained from Local Research Ethics Committees. Each family was contacted by hospital staff to provide information about the research and obtain consent to pass their details to the researcher. Families were then contacted by telephone to discuss further their willingness to participate in the study, to answer any questions they might have and to arrange a convenient appointment. Both parents in two-parent families were invited to participate. At the interview, written informed consent was obtained and parents were assured of confidentiality.

\section{Data analysis}

Principles and procedures of the constant comparative method guided data analysis (Glaser 1992, Strauss \& Corbin 1998). Data collection and analysis occurred concurrently, with codes and categories being inductively developed. Initially, the transcripts were read to obtain a sense of the whole story, prior to line-by-line coding using the NUD*IST computer program (Qualitative Solutions and Research, Ltd 1997). Similarities and differences in the codes were examined, they were clustered to create categories, which were then compared and contrasted in order to develop more inclusive categories. An account was developed to explain the relationships between categories, and the theory of 'being a parent' was generated. Analytical and self-reflective memos were recorded throughout the coding process to document the process and speculate about the data and ideas about the emerging codes and categories.

\section{Ensuring rigour}

Regular meetings were held between the co-authors throughout the fieldwork and analysis. A number of transcripts and the coding of the data were jointly reviewed as a means of enhancing theoretical sensitivity, uncovering any biases and clarifying interpretation. Credibility was also enhanced by prolonged engagement in the field. Throughout the study, we critically reflected on, and took into account, how we might have influenced the study through our assumptions, actions, feelings, relationships with participants and approach taken to the data. An audit trail outlined the research and the decisionmaking processes, with the evolution of the coding and analysis being presented in memos and in the record of the developing NUD*IST tree structure. Data were examined for rival explanations, and negative cases were identified and examined to identify the reasons for difference. The use of theoretical sampling maximised the range of information obtained.

\section{Findings}

\section{Context of parenting}

\section{Transformed meaning of home}

The home is a key cultural symbol, embodied with developmental, psychological and socio-cultural meanings and values (Rubinstein 1990, Williams 2002). Basic to the meaning of home are elements of privacy, safety, intimacy, control and liberty (Ruddick 1995, Twigg 1999). The home is also viewed as an embodiment of personal identity with personal meanings being ascribed to space, objects and daily routines (Twigg 1999, Williams 2002). Consequently, alteration of the home, either spatially or temporally, can have significance for individuals (Rubinstein 1990).

Parents' accounts revealed that the technology transformed the meaning of home, which were medicalized by the presence of equipment and the continual or frequent presence of home carers or professionals. Homes were invaded and dominated to various degrees by pieces of equipment and supplies, which led them to be seen by parents as medical environments. One mother described how she associated her child's bedroom with a 'mini-hospital' because of the presence of equipment:

She's got a cupboard in her bedroom that's totally full of everything she needs. Needles, syringes, gauze, everything we need for her. So it's like a medical cupboard. Actually her bedroom is like a minihospital. There is everything you can think of that we'd use in hospital is there. (Family A24: mother)

All parents experienced the intrusion of equipment and spatial alteration. Depending on the child's needs and the size of the home, the entire environment could be dominated by technology. One child who was continually dependent on a ventilator used the family living room as his bedroom. His mother's description of the consequences of this spatial reordering conveys how family life and the home were structured around the technology:

We had him in the lounge area in the other house, you know, his bed and his oxygen and his vent(ilator), all his stuff all in our lounge. The kids couldn't have their friends in because it wasn't then our lounge it was A's bedroom...there was just no space, you couldn't move...the kids would be sitting watching children's TV when they come in from school and A would be 'alarming' and you'd be giving him suction then you'd be giving him chest physio and the kids were, 'Mum, we are trying to watch the tele!'...Then you'd have his pipes and then you'd have his chair because he'd be connected up to his ventilator on his chair. So it's like, 'Will you sit still! Don't do that 
you are going to stand on him. Will you mind his pipes'. (Family A09: mother)

Homes were not only transformed by the presence of equipment but also by the personnel who accompanied the technology. This was particularly so for families who had teams of support workers working in their homes day and night. The home was no longer seen as a private sphere, a refuge from the outside world, but a public space where life was conducted alongside comparative strangers, with interactions open to public inspection and judgement. This lack of privacy shaped the conduct of parents and family life. Demonstrations of affection and family arguments were constrained as parents felt that workers could pass judgements on their lives:

You haven't got the freedom to talk about anything you want to because someone is always around. It's very compromising. I want to keep things to myself, really, and there are certain things you can't do. (Family A16: mother)

The presence of support workers also impinged on the social life of the family as entertaining of friends and family had to be carried out in the midst of the workers, care-giving and its associated technology. The technology therefore medicalized and shaped the experience of parenting.

\section{Nature of care-giving}

Parents' roles in care-giving were multi-faceted and involved managing their child's often unpredictable and complex medical condition, as well as organising home support services. The key feature was the nature of the care they were providing. In addition to the usual activities associated with parenting, they were performing a wide range of clinical procedures traditionally regarded as the domain of professionals, including administering oxygen; changing tracheostomy tubes; administering intravenous infusions; suctioning airways; passing naso-gastric tubes; and giving injections.

Performing clinical procedures on their own children was described as being the most distressing part of caregiving, because it could involve deliberately inflicting pain on their own child. Parents had to cope with both their own and the child's emotional reactions. Being agents of pain rather than providers of comfort and protection was distressing:

The thing that I find hard to cope with is that it's my son... and it's seeing him in distress that tears you apart inside, you know... O really struggles to breathe while you're doing it, and that's the bit I find hard to cope with. (Family A15: father)
To actually get it up their nose and making sure it was in the stomach, testing it was in the stomach and that distressed him. That upset me more because that distressed him more, rather than the actual tube change or the suction. (Family A02: mother)

The type of role played by parents in their child's care had consequences for how they experienced and defined parenting.

\section{Dual roles: parent and nurse}

Parents wanted to see themselves primarily as parents and did not want their relationship with their child to be defined by the nursing activities they undertook:

It's enough responsibility having a child anyway, with their school work and their development,...but obviously when you've got somebody with complex needs then you are doing the things that a nurse could do. It's quite difficult sort of getting into that role, but once you are into it then it's sort of separating it and being a mum at the same time. (Family A16: mother)

Another mother described how, during periods when she was not performing procedures, she could develop an image of herself as a parent. She could relate to him as a mother by engaging in usual parenting and family activities. However, this was disrupted by the clinical procedures, which led to her role reverting to that of what she termed 'carer':

Now I can be his mum...I can get with him and I can sit on the floor with him and we can watch tele(vision) with the others all together. Or we can go out together, we are just going to be a family. But then, come 8 o'clock, I've got to do his chest and I've got to do his physio and I've got to do his (naso-gastric) feeds. And then you're not his mum, you're his carer again (Family A09: mother)

Parents described a sense of resentment at the way in which their nursing role could dominate their parenting experience. They wanted to define themselves as parents and not nurses and have a parent-child relationship. One mother described how she felt that she had been a full-time nurse to her child and not a mother, due to the intensity of his needs and her care-giving role:

I was like a full-time nurse, I wasn't like a mother. That got to me...I didn't even know him as a mother - I'm his nurse you know. (Family A01: mother)

Only one parent did not portray the dual roles as problematic. She explained that, as her only child had been dependent upon technology from birth, she had never had a parenting experience that did not involve performing clinical procedures. However, it is not clear why she differed from the other first time parents in this respect. 


\section{Being a parent: parental care-giving and professional nursing}

\section{Jobs and lives}

One way in which parents differentiated their roles from professional nursing related to the context within which caregiving occurred. They saw care-giving as being a job for professional nurses, while for parents it was their entire lives. Nurses could return home at the end of their shift to their 'normal' lives and be removed from the intensity of continuous care-giving. However, for parents there was no such break, as care-giving was interwoven into their lives, and they distinguished between caring as a chosen occupation and caring within the context of love, duty and obligation:

You can walk into work, do your job, give suck outs, give chest physio, give (naso-gastric) feeds, but at the end of the day you can go home and be your normal little person in your normal little home, living your normal little life. Whereas this is ALL that is our life, constantly, all the time. It's not through choice, it's been handed out and that's what you've got to get on with. (Family A10: mother)

\section{Parental care-giving and emotional significance}

Parents' accounts revealed how, because they were providing care in the context of a parent-child relationship, performing clinical procedures was laden with emotional significance. Thus, while parents and nurses may perform the same procedures, they have different meanings. Parents contrasted their feelings of distress with what they assumed to be the routinized experiences of nurses carrying out similar procedures:

It's your child and you're causing them (through) discomfort and pain, and you're making them cry. So then that makes you feel terrible. But as a nurse, you know what I mean, it's just a client that needs something doing, next one along please. (Family A09: mother)

You just change from a parent into like a nurse, you know you lose, because if I had to look after O like a nurse, there wouldn't be the emotional connection, you know, that is my son, I do a wonderful job. It's the thing that I find hard to cope with...it's my son and it's seeing him when he aspirates and it's seeing him in distress and that tears you apart inside you know. (Family A15: mother)

How parents contrasted parental and professional care-giving resonates with analyses of caring in the sociology and social policy literature, which has identified that caring has dual dimensions (Graham 1983, Thomas 1993). This work suggests that caring can mean caring for (carrying out instrumental activities) and caring about a person (having caring feelings) (Graham 1983, Thomas 1993). Parents appear to see a link between these two dimensions in that the absence of an emotional connection ('caring about' dimension) between nurses and children influences how they give care (caring for).

Parents' emphasis on caring about their children was reflected in their discussions of the risks involved in caregiving and performing clinical procedures. They expressed fears that their actions could cause their child harm, and that they would then have to contend with feelings of guilt. As a consequence, in their accounts of care-giving they portrayed their care as of a higher standard than that of professionals. Their explanations for this again related to the fact that they were performing these procedures on their own children to whom they were strongly emotionally attached. Nurses were seen as not having to contend with the long-term implications of making mistakes:

I will not make mistakes. If I make mistakes, my daughter's life is in jeopardy. They don't look at it like that, they look at it as she's a number...if it was their own child, they wouldn't make that mistake. (Family A17: father).

Parents' accounts could be read as moral accounts, formulated to present themselves as competent and devoted parents (Baruch 1981), rather than as objective accurate historical records of care provision. Their value is that they indicate how parents contrast their own care with that of nurses.

\section{Individualized nature of parents' knowledge}

Parents also distinguished parenting from professional nursing in terms of the different types of knowledge that they and professionals, such as nurses, possessed and which underpinned care-giving. Parents associated their expertise with two different types of knowledge: the specialized medical knowledge associated with their child's condition and the medical technology that they had acquired formally from professionals in hospital, and the experiential knowledge derived from intensively caring for an individual child. This latter knowledge was described as enabling them to be aware of minute changes in their child's condition or behaviour that could indicate that they were becoming ill. However, parents perceived that professionals not only lacked experiential knowledge because of the absence of an in-depth continuous relationship with the child, but that they did not value this form of knowledge.

These findings have parallels with research examining parental knowledge in the context of everyday childcare and acute illness. This work has similarly noted that parental knowledge is of a different nature to the objective, scientific basis claimed for professional knowledge, and is developed 
through parents' close contact with their child (CunninghamBirley 1990, Callery 1997). Professionals' lack of recognition of experiential knowledge has been reported previously, and it has been proposed that this is because of inability to relate to knowledge that is not 'scientifically' derived and based on disease concepts, rather than knowledge rooted in the experience of illness (Stacey 1988, Lauritzen 1997).

Parents described how their experiential knowledge, combined with their medical knowledge, enabled them to provide individualized care for their child, for example, adapting treatment regimens to meet individual needs. They felt that professional directives for the administration of treatments were not based on the experiential knowledge of the individual child that was essential for providing care appropriately. Consequently, there was potential for conflict between professionals and parents over what was 'appropriate' care.

\section{Conclusions}

Caring at home for a technology-dependent child involved parents in carrying out complex clinical procedures which, in a hospital environment, would be undertaken by professionals, particularly nurses. Parents combined being mothers and fathers to their child with the provision of skilled nursing care on which their child's wellbeing and survival depended. The latter involved not only acquiring technical competencies, but also the expertise to make complex clinical decisions. The resulting reshaping and redefining of parenthood that occurred in this context was a consequence of social change in the form of medical advances which have enabled complex and technical care to be provided in people's homes. In response to these advances, it appears that additional responsibilities have been defined as being appropriate for parents. Thus, it is not just medical machinery that is being transferred from hospital to home, but roles and responsibilities. Transferring clinical skills in this way is more complex than might be assumed by professionals, as it alters the meaning of parenting itself.

Nurses and other professionals need to recognize that learning and giving care of this nature for their child has a substantial emotional dimension for parents and does not only involve the competent performance of psychomotor skills. Parents need opportunities to discuss their feelings about providing care and what it means for their self-image as parents and the nature of the relationship with their child. In addition, nurses and other professionals need to take account of how parents construct parenting, and support the strategies they use in order to see themselves as parents first and foremost. Therefore, they need to spend time listening to parents and discussing their expectations and experiences of parenting and the coping strategies they are using, or perhaps could use, to see themselves as parents rather than nurses. Thus, a key nursing role is supporting the strategies that parents use, either directly or by referrals to other services. Nurses and others need to be aware of their own assumptions and definitions of 'normal' parenting, and be conscious of these in their interactions with parents.

Parents drew a sharp distinction between parenting and nursing, and this contrast was important in their presentation of themselves as parents. Central to their definitions was the emotional connection between parent and child, which meant that caregiving had a significant personal emotional impact. Although parents' views of how nurses and other professionals provide care may have been polarized as a means of distinguishing parental and professional care-giving, their accounts may tell us something about how they perceive that nurses give care for their children, i.e. that it can be impersonal, routinized and associated with risk-taking. Their accounts also raise questions about whether the nurses' caregiving is individualized. Other research in the care of adults suggests that, while the assessment process may be individualized, the actual process of care-giving may not be (Waters \& Easton 1999). Nurses working with families need to consider whether their care is individualized to the needs of the child and family, and to reflect on whether any 'shortcuts' fall outside the boundaries of safe practice. They certainly need to be aware that this group of parents are themselves experts in these clinical procedures and may be scrutinizing their performance. Consequently, 'acceptable short-cuts' need to be explained to parents so that they are not perceived as putting their child's health at risk. The distinction parents made between themselves and nurses also raises questions about how nurses appear to relate to children - the 'caring about' dimension. Nurses may well have feelings of affection towards children, and demonstrating this in how they give care and relate to children appears to be important to parents.

Parental expertise extends beyond the 'scientific' knowledge of their child's particular condition and the technology on which they are dependent. It is grounded in individualized knowledge about their child that enables them to be aware of small changes in their child's health and to 'fine-tune' caregiving and therapies to their individual needs. Such a management role is in keeping with recent UK government policy, which has encouraged healthcare providers to view chronically ill patients as experts in their own health who should be encouraged by professionals to manage their own conditions (albeit within the parameters of the medical regime') (Department of Health 2001, p. 22). This policy 


\section{What is already known about this topic}

- Caring for a technology-dependent child has a significant social and emotional impact on parents and families, which parents actively attempt to manage.

- Obtaining appropriate and co-ordinated support from services can be problematic for parents.

\section{What this paper adds}

- Parenting a child who is dependent on medical technology extends 'normative' ideas of parenting and parenting roles.

- These parents construct parenting as having both parenting and nursing dimensions.

- Parents manage this tension in order to define themselves as parents.

views patients and professionals as having their own areas of knowledge and expertise, but as working together in partnership to optimize the person's well-being. In addition, this policy is based on a philosophy that offers opportunities for improved patient-professional relationships. However, because lay people and professionals draw on different types of knowledge and expertise and use different types of logic when making decisions about treatments, agreement between the two parties cannot be assumed. Moreover, this policy neither acknowledges nor addresses the inherent power asymmetries which have been identified as a barrier to participation. In the context of children's health care, professionals have a powerful lever in attempting to ensure that parents comply with their directives in terms of child protection. It is therefore imperative that they distinguish between 'constructive non-compliance' and occasions where a child's health and well-being are at risk. Indeed, recognition of parents' individualized, experientially derived, expertise should underpin professional relationships, along with awareness of how their dual role transforms their relationship with their child and their parenting identity.

\section{Acknowledgements}

We would like to thank the participants who so willing gave time to share their experiences, and the nurse specialists and consultant paediatricians who assisted with recruiting families. The study was commissioned by the Department of Health as part of its 'Supporting Parenting' research initiative. However, the views expressed in this paper are those of the authors alone.

\section{Author contributions}

SK, CG and PC contributed to the study conception and design, data analysis and drafting of the manuscript.

\section{References}

Arendell T.E. (1997) A social constructionist approach to parenting. In Contemporary Parenting: Challenges and Issues (Arendell T., ed.), Sage, Thousand Oaks, CA.

Atkin K. \& Ahmad W.I.U. (2000) Family care-giving and chronic illness: how parents cope with a child with a sickle cell disorder or Thalassaemia. Health and Social Care in the Community 8(1), 57-69.

Baruch G. (1981) Moral tales: parents' stories of their encounters with the health professions. Sociology of Health and Illness 3, 275 296.

Bjornberg U.E. (1992) Parenting in transition: an introduction and summary. In European Parents in the 1990s (Bjornberg U.E., ed.), Transaction Publishers, New Brunswick, NJ, pp. 1-25.

Callery P. (1997) Maternal knowledge and professional knowledge: co-operation and conflict in the care of sick children. International Journal of Nursing Studies 3(1), 27-34.

Cohen M. (1999) The technology-dependent child and the socially marginalised family: a provisional framework. Qualitative Health Research 9(5), 654-668.

Cunningham-Birley S. (1990) Mothers' beliefs about and perceptions of their children's illnesses. In Readings in Medical Sociology (Cunningham-Birley S. \& McKeganey N., eds), Tavistock, London, pp. 85-109.

Department of Health (2001) The Expert Patient: A New Approach to Chronic Disease Management for the 21st Century. Department of Health, London.

Diehl S., Moffitt K. \& Wade S.M. (1991) Focus group interviews with parents of children with medically complex needs: an intimate look at their perceptions and feelings. Children's Health Care 20(3), 170-178.

Glaser B. (1992) Emergence vs Forcing: Basics of Grounded Theory Analysis. The Sociology Press, Mill Valley, CA.

Glenn E. (1994) Mothering: Ideology, Experience and Agency. Routledge, New York.

Graham H. (1983) Caring: a labour of love. In A Labour of Love: Women, Work and Caring (Finch J. \& Groves D., eds), Routledge and Kegan Paul, London.

Gregory S. (1994) Challenging motherhood: mothers and their deaf children. In: Motherhood: Meanings, Practices and Ideologies, 2nd edn (Phoenix A., Woollett A. \& Lloyd E., eds). Sage, London, pp. 66-85.

Harkness S., Super C.M., Keefer C.H., Raghaven C.S. \& Campbell E.K. (1996) Ask the doctor: the negotiation of cultural models in american parent-paediatrician discourse. In Parents' Cultural Belief Systems (Harkness S. \& Super C.M., eds), Guilford Press, New York, pp. 289-310.

Horowitz J.A. (1993) A conceptualisation of parenting: examining the single parent family. Marriage and Family Review 20(1/2), 43-70 (cited by Arendell).

Jennings P. (1990) Caring for a child with a tracheostomy Nursing Standard 4(30), 24-26 and 4(32), 38-40. 
Kirk S. (1999) Caring for children with specialised health care needs in the community: the challenges for primary care. Health and Social Care in the Community 7(5), 350-357.

Lauritzen S.O. (1997) Notions of child health: mothers' accounts of health in young babies. Sociology of Health and Illness 19(4), 436456.

Leonard B., Brust J.D. \& Nelson R. (1993) Parental distress: caring for medically fragile children. Journal of Pediatric Nursing 8(1), 22-30.

McKeever P. (1991) Mothering chronically-ill technology-dependent children: an analysis using critical theory, PhD Thesis. York University, Toronto, Canada.

Patterson J., Jernell J., Leonard B. \& Titus J.C. (1994) Caring for medically fragile children at home: the parent professional relationship. Journal of Pediatric Nursing 9(2), 98-106.

Petr C.G., Murdock B. \& Chapin R. (1995) Home care for children dependent on medical technology: the family perspective. Social Work in Health Care 21(1), 5-22.

Quah S.R. (1990) The Family as an Asset. Times Academic Press, Singapore.

Qualitative Solutions and Research, Ltd (1997) QSR NUD*IST (version 4) [Windows]. Qualitative Solutions and Research, Melbourne.

Rapoport R., Rapoport R. \& Strelitz Z. (1978) Fathers, Mothers and Others. Routledge and Kegan Paul, London.

Rubinstein R.L. (1990) Culture and disorder in the home care experience: the home as sickroom. In The Home Care Experience (Gubrium J. \& Sanker A., eds). Sage, Newbury Park, CA, pp. 37-57.

Ruddick W. (1995) Transforming homes and hospitals. In Bringing the Hospital Home (Arras J., ed.), John Hopkins University Press, Baltimore, MD, pp. 166-179.

Stacey M. (1988) The Sociology of Health and Illness. Routledge, London.
Strauss A. \& Corbin J. (1998) Basics of Qualitative Research: Techniques and Procedures for Developing Grounded Theory Procedures, 2nd edn. Sage, Thousand Oaks, CA.

Teague B.R., Fleming J., Castle A., Kiernan B., Lobo M., Riggs S. \& Wolfe J. (1993) High tech home care for children with chronic health conditions: a pilot study. Journal of Pediatric Nursing 8(4), 226-232.

Thomas C. (1993) Deconstructing concepts of care. Sociology 27(4), 649-669.

Townsley R. \& Robinson C. (2000) Food For Thought: Effective Support for Families Caring for a Child Who is Tube Fed. Doveton Press, Norah Fry Research Centre, University of Bristol, Bristol.

Twigg J. (1999) The spatial ordering of care: public and private in bathing support at home. Sociology of Health and Illness 21(4), 381-400.

Voysey M. (1975) A Constant Burden: The Reconstitution of Family Life. Routledge and Kegan Paul, London.

Waters K. \& Easton N. (1999) Individualised care: is it possible to plan and carry out? Journal of Advanced Nursing 29(1), 79-87.

Williams A. (2002) Changing geographies of care: employing the concept of therapeutic landscapes as a framework in examining home space. Social Science and Medicine 55, 141-154.

Wilson S., Morse J.M. \& Penrod J. (1998) Absolute involvement: the experiences of mothers of ventilator-dependent children. Health and Social Care in the Community 6(4), 224-233.

Young L., Creighton D. \& Sauve R. (1988) The needs of families of infants discharged home with continuous oxygen therapy. Journal of Obstetric, Gynaecological and Neonatal Nursing 17(3), 187193.

Youngblut J., Brennan P. \& Swegart L. (1994) Families with medically fragile children: an exploratory study. Pediatric Nursing 20(5), 463-468. 